\title{
EDUCAÇÃO AMBIENTAL NA EFETIVAÇÃO DE PRÁTICAS ECOLÓGICAS: UM ESTUDO DE CASO SOBRE PRÁTICAS ECOLÓGICAS E COLETA SELETIVA NA UNIVERSIDADE ESTADUAL DA PARAÍBA
}

Vamberto Oliveira de Souza ${ }^{1}$

Resumo: O objetivo deste estudo se propõe em analisar a relevância da educação ambiental na efetivação do sistema de coleta de lixo, bem como, as práticas ecológicas adotadas pela instituição. A metodologia abordada no primeiro momento da pesquisa foi baseada no processo de observação de campo e no segundo momento foi realizada uma pesquisa documental. Durante a pesquisa foi observado que, infelizmente a coleta seletiva de lixo na Universidade Estadual da Paraíba ainda é falha, pois foram encontradas bastantes irregularidades em relação à frequência da coleta do lixo e a disposição dos coletores no campus da universidade. A educação ambiental, nesse caso, seria uma alternativa importante para resolução do problema.

Palavras-chave: Educação Ambiental; Práticas Ecológicas; Coleta seletiva.

${ }^{1}$ Universidade Estadual da Paraíba. E-mail:vamberto_@live.com 


\section{Introdução}

Com o agravamento da problemática do lixo e seu poder de degradação do meio ambiente, foi preciso trabalhar a conscientização da sociedade sobre os danos que o mesmo pode causar aos seres humanos e animais. Surgindo assim à coleta seletiva dos resíduos sólidos como solução para tal problema. A coleta seletiva pode ser definida como uma forma de separação prévia de possíveis materiais para o reaproveitamento (PIERONI apud CAMPOS, 1994), também considerada como uma ação de caráter emergencial e imprescindível em busca da sustentabilidade. A coleta seletiva não esteve presente somente neste século mais fez parte da historia, durante a segunda guerra mundial todos os países reciclavam, principalmente metais para a indústria bélica. Porém a coleta seletiva na Europa iniciou-se na Itália, em 1941, devido às dificuldades marcada pelas grandes guerras (SANTOS, 1995).

A coleta seletiva, no Brasil iniciou-se na cidade de Niterói, no bairro de São Francisco, em abril de 1985, como o primeiro projeto documentado e sistemático. Diante disto começou-se a crescer o número de municípios que passou a praticar a coleta, foram identificados 82 programas de coleta seletiva em 1994, iniciados, a partir de 1990 (CEMPRE, 1995). A Alemanha, Japão, Holanda, Canadá e os Estados Unidos da América, são considerados os países que mais utilizam das práticas ecológicas, como exemplo de tais práticas está à coleta seletiva, que reduz o volume dos resíduos sólidos urbanos, tão nocivos à saúde humana.

Práticas Ecológicas são maneiras de agir visando na preservação do meio ambiente e a melhor utilização dos recursos disponíveis diminuindo assim os impactos ambientais. Dentre os problemas que competem para a crise ambiental, notadamente em municípios de grande porte populacional, destacase a falta de gestão de resíduos sólidos, a qual compromete os sistemas naturais, sociais e econômicos e a saúde do próprio homem. A implantação desse sistema constitui uma importante estratégia para amenizar tal degradação ambiental, no entanto, na ausência de Educação Ambiental o alcance deste objetivo não será possível (SILVA, 2009).

A coleta do lixo é uma responsabilidade do governo e um direito da sociedade, mais o que ocorre é que tal coleta está se tornando ineficaz, tanto pelo recolhimento inadequado, quanto pela falta de um espaço apropriado para armazenagem dos resíduos. A coleta seletiva é uma alternativa ecologicamente correta que desvia, do destino em aterros sanitários ou lixões, resíduos sólidos que poderiam ser reciclados. No Brasil existe coleta seletiva em cerca de 135 cidades, de acordo com o professor Sabetai Calderoni (autor do livro Os Bilhões Perdidos no lixo Ed. Humanitas). Na maior parte dos casos a coleta é realizada pelos catadores organizados em cooperativas ou associações de bairro, onde existe ou existiu alguma Educação Ambiental, que despertou essas ações ambientais. 
A Coleta seletiva deve ser vista como uma corrente de três elos. Se um deles não for planejado a tendência é o programa de coleta seletiva não perseverar. O planejamento deve ser feito do fim para o começo da cadeia. Ou seja: primeiro pensar em qual será a destinação, depois a logística e por fim o programa de educação ambiental.

A proposta de Educação Ambiental é resgatar a necessidade de participação da sociedade para uma solução conjunta na solução dos problemas ambientais, harmonizando as ações humanas em relação à sua própria espécie e aos demais seres do planeta. A inclusão da Educação Ambiental nas instituições de ensino tem o propósito de uma reestruturação da educação em direção à sustentabilidade, incentivo à gestão escolar dinâmica, estimulando a implantação dos projetos em Educação Ambiental (RUIZ et al., 2005).

Desse modo, surge a inquietação pautada ao seguinte problema: A educação ambiental tem relevância na efetivação de práticas ecológicas e de coleta seletiva na Universidade Estadual da Paraíba? Para isso, o objetivo deste estudo se propõe em analisar a relevância da educação ambiental na efetivação do sistema de coleta de lixo, bem como, as práticas ecológicas adotadas pela instituição.

Para atender a tal objetivo primeiramente foi analisado o próprio sistema de coleta seletiva, com o propósito de entender o seu funcionamento. Logo após foi identificado às práticas de educação ambiental oferecida pela instituição. Dessa forma, será analisada a relevância e a influência da Educação Ambiental na efetivação no processo de coleta seletiva.

As disseminações das campanhas educativas referentes ao processo da coleta seletiva dos resíduos sólidos são uma forma de contribuir para a diminuição da degradação do meio ambiente, causada pelo excesso de lixo nas zonas urbanas. A educação ambiental surge como uma ferramenta para o desenvolvimento sustentável, com intuito de que as práticas sustentáveis funcionem, e que alcancem os seus objetivos, tendo em vista que uma sociedade educada ambientalmente possui um caráter crítico, sendo inserida como uma educação interdisciplinar de saberes e atitudes, envolvendo a participação do individuo na conscientização de novas formas para lutar por um equilíbrio entre o homem e o meio ambiente.

\section{Educação Ambiental}

O conceito sobre o desenvolvimento sustentável abordado pela Comissão Mundial sobre Meio Ambiente e Desenvolvimento (CNUMAD, 1992), afirma que o desenvolvimento sustentável satisfaz às necessidades do presente, sem comprometer as possíveis necessidades das gerações futuras.

O desenvolvimento sustentável tem como grande aliada e disseminadora dos seus conceitos a Educação, que está relacionada com a formação de base da sociedade. Levando isso em consideração, notou-se que 
colocar a educação como uma ferramenta de auxilio para o desenvolvimento sustentável agregaria valor para formação da conscientização e mudança de comportamento visando melhores práticas advindas da sociedade (LEFF, 1999).

A educação para o desenvolvimento sustentável necessita de novos conteúdos e orientações, através de novas práticas pedagógicas, na qual auxilia na criação de uma nova relação de produção do conhecimento e nos processos de circulação, transmissão e disseminação do saber ambiental, o que é fundamental para a efetivação das várias práticas ambientais existentes, que possuem como objetivo uma alternativa que degrada menos o meio ambiente. Mais do que se limitar a uma educação relacionada somente ao meio ambiente, a educação para a sustentabilidade está ligada a interdisciplinaridade, de relacionar o social ao meio ambiente, sem descartar o econômico, visando à sustentabilidade e o bem-estar da sociedade.

As campanhas educativas colaboram para mobilizar a sociedade, para sua participação efetiva e ativa na implantação da coleta seletiva de resíduos sólidos, separando os materiais recicláveis e/ou reutilizáveis diretamente na fonte de geração. Desta forma, acreditando na Educação Ambiental como processo educativo, permanente e contínuo, que visa desenvolver uma filosofia de vida ética e moral, de maior harmonia e respeito com a natureza e entre os homens, propiciando conhecimentos e o exercício da cidadania para uma atuação crítica e consciente dos indivíduos e grupos, tem esta como chave para a implementação de projetos direcionados aos resíduos sólidos (FERREIRA, 2008).

A Educação Ambiental constitui um importante instrumento de mobilização da comunidade para mudança de hábitos e comportamentos, especialmente em projetos relacionados à coleta seletiva. Entre seus objetivos, princípios e finalidades expressos na Conferência de Tbilisi, de acordo com Dias (1994) e Guimarães (1995), estão:

- Ser um processo contínuo e permanente, iniciando em nível préescolar e estendendo-se por todas as etapas da educação formal e informal, adotando a perspectiva interdisciplinar e utilizando as especificidades de cada matéria de modo a analisar os problemas ambientais através de uma ótica global e equilibrada;

- Examinar as principais questões relativas ao ambiente tanto do ponto de vista local como nacional, regional e internacional, para que os envolvidos tomem conhecimento das condições ambientais de outras regiões;

- Inter-relacionar os processos de sensibilização, aquisição de conhecimentos, habilidades para resolver problemas e especificações dos valores relativos ao ambiente em todas as idades, enfatizando, sobretudo a sensibilidade dos indivíduos em relação ao meio ambiente de sua própria comunidade; 
- Levar em conta a totalidade do ambiente, ou seja, considerar os aspectos naturais e construídos pelo homem, tecnológicos e sociais, econômicos, políticos, histórico-culturais, estéticos.

Contudo, Ab'Saber (1991), considera que a Educação Ambiental constitui "um processo que envolve um vigoroso esforço de recuperação de realidades, nada simples. Uma ação, entre missionária e utópica, destinada a reformular comportamentos humanos e recriar valores perdidos ou jamais alcançados. Um esforço permanente na reflexão sobre o destino do homem de todos os homens - face à harmonia das condições naturais e o futuro do planeta 'vivente', por excelência. Um processo de Educação que garante um compromisso com o futuro. Envolvendo uma nova filosofia de vida. E, um novo ideário comportamental, tanto em âmbito individual, quanto na escala coletiva"

\section{Práticas ecológicas}

As práticas ecológicas estão relacionadas aos conceitos de cidadania e desenvolvimento sustentável, resgatando o papel de agente transformador do ser humano. Tais práticas são maneiras de agir visando à preservação do meio ambiente e a melhor utilização dos recursos disponíveis diminuindo assim, os impactos ambientais. Essas práticas são utilizadas para manter um equilíbrio entre a sociedade e o meio ambiente. A ideia de práticas ecológicas destacam, segundo Irmão (2006, p.17), "a qualidade de vida da população, transcendendo o conceito convencional da riqueza material e incluindo na análise a preocupação sobre meio ambiente e meio social para avaliar a sustentabilidade para as gerações futuras".

Nesse sentido, as práticas ecológicas surgem como ferramentas utilizadas para promover o desenvolvimento sustentável, inserindo ações interdisciplinares de saberes e atitudes que envolvem a participação do individuo na conscientização de novas formas para lutar por um equilíbrio entre o homem e o meio ambiente.

Nesse contexto observa-se o lixo como um agente importante de exemplo para se trabalhar com as práticas ecológicas. O lixo é um material indesejado onde todos querem descarta-lo, até mesmo pagam para se verem livre desse mal (CALDERONI, 1997, p.25). O destino final do lixo é um dos principais agentes que deterioram o meio ambiente.

Continuando nessa perspectiva, o lixo é formado por resíduos sólidos, resultantes das atividades humanas, Pereira Neto (1999, p.9), trata bem uma definição para o lixo como, "uma massa heterogenia de resíduos sólidos, resultantes das atividades humanas, os quais podem ser reciclados e parcialmente utilizados, gerando entre outros benefícios, proteção à saúde pública, economia de energia e de recursos naturais". Uma das soluções para 
impedir a deterioração, seria a coleta seletiva e a reciclagem desses resíduos sólidos, evitando a ampliação de aterros ou lixões.

A reciclagem é uma forma de educar e despertar nas pessoas a consciência de preservação do meio ambiente, estimulando assim o sentimento do poder de transformação. Para o autor (CALDERONI, 1996), com a reciclagem se diminui a quantidade de lixo produzido e se reaproveita de diversos materiais evitando o acúmulo do lixo em lixões e aterros.

Nos dias atuais as discussões sobre o lixo estão se tornando cada vez mais presentes nos encontros científicos, e agora chegando ao senado onde foi aprovado pelo plenário o projeto de lei (PLS 354/89), que institui a Política Nacional de Resíduos Sólidos. Basicamente, a nova lei regula a reciclagem, disciplina e o manejo dos resíduos. De acordo com dados que embasaram o projeto, do lixo produzido no Brasil, 59\% vão para os "lixões". Apenas 13\% do lixo têm destinação correta, em aterros sanitários. Dos 5.564 municípios brasileiros, apenas 405 tinham serviço de coleta seletiva em 2008. Com a nova lei, o que muda principalmente é que o projeto estabelece a responsabilidade compartilhada entre governo, indústria, comércio e consumidor final no gerenciamento e na gestão dos resíduos sólidos, onde será tratado de forma mais ampla através de campanhas agora apoiadas por lei.

Sendo assim, e levando em consideração que a questão do lixo é de caráter básico, seja do jovem ou criança, do cidadão, do trabalhador, a educação será essencial através de ações visíveis e efetivas, onde se apresente resultados visíveis a toda sociedade, que é o caso da coleta seletiva e da organização de catadores.

A necessidade de estimular a sociedade sobre as questões ambientes tem sido muito abordada, principalmente na comunidade acadêmica, visto que as instituições de ensino superior possuem um vasto campo para estudos e projeto de conscientização, relacionando assim as práticas ecológicas que cada indivíduo pode praticar. Segundo Castro (2000) a universidade é vista como um fator relevante para a produção do saber, e que deveria estar à frente das transformações na sociedade, visto que apesar dessa construção do saber a universidade não deve ser observada só como um local do "saber pelo saber" em busca de soluções socioambientais imediatas, mais sim a preocupação que o conhecimento deve ser disseminado, o que seria um fator decisivo quando se fala em prejuízos para as futuras gerações.

\section{Metodologia}

Como forma de buscar atender a finalidade da pesquisa, o objetivo deste estudo se propõe em analisar a relevância da educação ambiental na efetivação do sistema de coleta seletiva implantado na Universidade Estadual da Paraíba. Para atender a tal objetivo primeiramente foi analisado o próprio sistema de coleta seletiva. Logo após foi identificado às práticas de educação ambiental oferecida pela instituição. 
A metodologia utilizada no primeiro momento foi baseada no processo de observação de campo, onde foi feita uma coleta de dados para conseguir informações sobre determinados aspectos da realidade, ajudando 0 pesquisador a "identificar e obter provas a respeito de objetivos sobre os quais os indivíduos não têm consciência, mas que orientam seu comportamento" (LAKATOS, 1996). A observação também obriga o pesquisador a ter um contato mais direto com a realidade. Esta técnica é denominada observação assistemática, onde o pesquisador procura recolher e registrar os fatos da realidade. Geralmente este tipo de observação é empregado em estudos exploratórios sobre o campo a ser pesquisado.

No segundo momento foi realizada uma pesquisa documental onde se buscou identificar as práticas ecológicas oferecidas pela instituição. A análise documental favorece a observação do processo de maturação ou de evolução de indivíduos, grupos, conceitos, conhecimentos, comportamentos, mentalidades, práticas, entre outros. (CELLARD, 2008). Nesse sentido, a pesquisa se propôs a buscar as práticas ecológicas desde a graduação e seus envolvimentos ambientais até os programas de pós-graduação, através de documentos que explicitassem o modo como a universidade trata dessas questões. Buscou-se projetos de extensão que falasses de práticas ecológicas na sociedade, programas de conscientização e dentre outros programas que na pesquisa documental pode-se observar.

A Universidade Estadual da Paraíba ainda disponibiliza algumas dessas informações na sua própria página na web, essa página foi bastante importante para a apuração de muitas das informações para efetivação desse trabalho. A pesquisa documental ainda se mostrou importante, pois, permitiu sintetizar informações, determinar tendências e por fim, fazer inferência e análises com relação a nossa pesquisa.

\section{Análise de dados}

Levando em consideração a metodologia abordada, a análise dos dados está divida em duas grandes partes, no primeiro momento utilizou-se a análise de observação de campo. E no segundo momento foram pesquisados às práticas de educação ambiental oferecida pela instituição.

\section{Análise e observação de campo}

A pesquisa foi realizada na Universidade Estadual da Paraíba, CAMPUS I (Campina Grande), onde foram encontrados em média cinquenta e seis pontos de coletas seletiva distribuídos pelo campus: CEDUC - Centro de Educação (História, Geografia, Letras, pedagogia e filosofia), Pelo CCSA Centro de Ciências Sociais Aplicadas (Administração, Ciências Contábeis, Comunicação social e serviço social), pelo CCBS - Centro de Ciências Biológicas e da Saúde (Ciências Biológicas, Educação Física, Enfermagem, Farmácia, Fisioterapia, Odontologia e Psicologia), pelo CCJ - Centro de 
Ciências Jurídicas (Direito), pelo CCT - Centro de Ciências da tecnologia (Licenciatura em Matemática, Física, Química e Computação, Bacharelado em Estatística e Química Industrial e Engenharia Sanitária e Ambiental).

Não há uma fórmula universal de como utilizar a coleta seletiva, cada lugar tem uma realidade e precisa-se inicialmente de um diagnóstico local para defini-la. Contudo, fica perceptível que a coleta seletiva é bem mais que colocar lixeiras coloridas em um determinado local. Nesse sentido, percebe-se a má distribuição dos coletores, pois foram observados ambientes da instituição onde possuem menos fluxo de pessoas com o número de coletores bem menores, em comparação com corredores que possuem pouco fluxo de pessoas e muitos coletores. Nesse caso, a educação ambiental seria uma alternativa para resolução do problema, pois a Educação Ambiental constitui um importante instrumento de mobilização da comunidade para mudança de hábitos e comportamentos, especialmente em projetos relacionados à coleta seletiva (DIAS, 1994).

Como por exemplo, nos centros: CEDUC e CCSA, foram encontrados vinte e quatro pontos de coleta, oito destes pontos estavam incompletos, isto é, não estavam com as cinco divisões (orgânico, plástico, vidro, papel, metal), o que prejudica na eficiência do processo. Este problema foi repetido varias vezes, nos pontos de coletas próximo as escadas destes centros onde foram encontrados apenas um coletor (por exemplo, o de vidro), estimulando as pessoas a depositarem os materiais nos depósitos inadequados. Mais uma vez, observa-se a questão da educação ambiental, nesse caso, através de cursos, palestras coletivas, audições e reuniões para começar a conscientizar a comunidade acadêmica.

\section{Práticas ecológicas oferecidas pela instituição}

A Universidade Estadual da Paraíba tem como missão "formar cidadãos, mediante a produção e a socialização do conhecimento, contribuindo para o desenvolvimento Educacional e Sócio-cultural da Região Nordeste, particularmente do Estado da Paraíba, em sintonia com o Plano de Desenvolvimento Sustentável Estadual".

O ensino de graduação da UEPB contribui para a formação do cidadão crítico e socialmente comprometido - um ser múltiplo - solidariamente integrado à sociedade, com responsabilidade social, comportamento ético e competências profissionais básicas. Na instituição foi identificado um curso de graduação voltado para temática Ambiental, Engenharia Sanitária e Ambiental, o que fortalece a disseminação do conhecimento sobre o desenvolvimento sustentável. Porém, a disseminação de informações ligadas à Educação Ambiental ainda é insuficiente na graduação. Observa-se que a instituição poderia disseminar tais informações através de ciclos de palestras, minicursos e exposição dos projetos desenvolvidos nos cursos ligados ao meio ambiente e sua preservação. 
A pesquisa científica na instituição otimizada a partir da ampliação da interface entre a graduação e a pós-graduação, deverá priorizar as áreas de conhecimento e as respectivas linhas de pesquisa dos cursos de pósgraduação. Identificou-se uma revista editada pelo Centro de Ciências Sociais Aplicadas da Universidade Estadual da Paraíba (Qualit@s Revista Eletrônica), que aborda alguns temas relacionados com 0 meio ambiente e sua preservação. Através dessas pesquisas dos diversos cursos da UEPB Campus I, é possível a propagação do conhecimento, tanto em revistas, quanto em eventos científicos. Uma iniciativa propulsora da educação ambiental na instituição seria uma amostra dos trabalhos publicados na revista, dando assim uma oportunidade aos cursos de graduação da UEPB conhecerem os artigos científicos, compartilhando o conhecimento gerado na revista eletrônica.

A extensão universitária através dos programas institucionais articulados com o ensino e/ou pesquisa, deverá se constituir no instrumento essencial para a inserção da UEPB no meio social, ampliando as ações sintonizadas com a comunidade. Como exemplo pode-se citar a Semana de Extensão - SEMEX, onde são apresentados trabalhos realizados durante 0 ano vigente sobre diversos temas, dentre eles a problemática Ambiental, promovendo uma ampla reflexão da extensão enquanto lugar de produção do conhecimento e instância de formação do aluno, contribuindo para o fortalecimento da dimensão extensionista do tripé indissociável, ensino, pesquisa e extensão.

Os cursos de pós-graduação deverão contribuir para a formação do pesquisador e qualificar para o exercício do magistério superior, priorizando linhas de pesquisa contextualizadas com a realidade regional e estadual. Como os problemas ambientais estão tomando forças com o passar do tempo, como exemplo o mestrado acadêmico, Ecologia e Conservação, onde são formados profissionais habilitados a desenvolver atividades de pesquisa e desenvolvimento tecnológico, ensino e extensão na área da Ecologia e Conservação.

\section{Considerações finais}

Hoje em dia em muitos lugares do mundo, ainda existem pessoas que não se importam com a grande quantidade de lixo descartado, e muito menos com a separação adequada destes resíduos. A correta separação do lixo e a coleta seletiva ajudarão a melhorar a qualidade de vida das pessoas, preservando assim o meio ambiente.

A educação está ligada a conscientização critica da sociedade, implicando em uma coleta de lixo mais eficiente, pois a educação de base influência na criação dos hábitos e mudanças do comportamento da população. As Instituições de Ensino Superior tem uma responsabilidade social de disseminar o conhecimento e a informação para a sociedade agindo assim como um agente modificador. 
Durante a pesquisa foi observado que infelizmente a coleta seletiva de lixo na Universidade Estadual da Paraíba ainda é falha, pois foram encontradas bastantes irregularidades em relação à frequência da coleta do lixo, a colaboração dos estudantes em relação à coleta seletiva, ao recolhimento, treinamento e acompanhamento por parte da instituição, causando assim a ineficácia do processo de coleta seletiva do lixo tornando o sistema de forma geral falho.

Diante das análises, percebe-se desde a observação de campo e a pesquisa documental das práticas ecológicas que, a Universidade Estadual da Paraíba se preocupa sim com as suas práticas ecológicas, porém, ainda é muito pouco em relação à dimensão da universidade.

Percebe-se ainda que, existe a falta de cursos e a própria capacitação em prol da coleta seletiva na universidade, algo que é considerado uma ação mínima na universidade. Toda essa análise foi pautada na observação de campo, onde as deficiências encontradas são as causas do mau funcionamento do sistema de coleta do lixo. A educação ambiental, nesse caso, seria uma alternativa importante para resolução do problema. Explorar questões referentes à importância da coleta seletiva, e a maneira correta de utilizar o processo através de cursos, palestras coletivas, audições e reuniões seriam uma medida eficaz nessa questão, pois todos os cursos de graduação estariam interligados com a coleta seletiva e as questões ambientais em torno da universidade.

Levando em consideração o que foi esclarecido, a UEPB poderia repensar sobre a sua gestão como da coleta seletiva do lixo, em relação a:

- Frequência da coleta: Pode-se pensar em criar políticas que aperfeiçoem o processo de recolhimento estabelecendo horários adequados para tal coleta, evitando assim o acúmulo do lixo.

- Colaboração dos discentes: A instituição poderia criar palestras e minicursos com o propósito de disseminar educação e conscientização em relação ás práticas ambientais.

- Recolhimento, treinamento e acompanhamento: Deveria haver uma maior participação da instituição em relação ao tema, criando assim um curso de capacitação para os colaboradores envolvidos neste processo de coleta seletiva, bem como um acompanhamento com a finalidade de dar mais eficiência ao processo.

Perante isto fica perceptível que a participação ativa da Universidade Estadual da Paraíba é um fator primordial para que a coleta seletiva seja funcional, a instituição é o sistema em estudo podendo ser divido em três partes a serem analisadas: A coleta seletiva de lixo, Discentes e os Servidores. Deve-se dar a devida importância a cada uma das partes envolvidas, para que o sistema de fato se torne eficiente. 
Contudo, a coleta seletiva pode ser considerada uma politica eficaz ser for aplicada de forma correta, caracterizada como uma das soluções para o problema do lixo, pois são através dessa coleta seletiva que se podem reaproveitar os resíduos sólidos diminuindo assim o acúmulo desse material nocivo ao meio ambiente. Seria importante o investimento em outras práticas ecológicas como forma de promover uma diversidade sustentável a partir da atuação da universidade na sociedade.

\section{Referências}

AGENDA 21 (1992). Disponível em: www.crescentefertil.org.br/agenda21/index2.htm. Acesso em: 20 jul. 2005.

AKATU. 2011. Disponível em: http://naturezasocial.com/?p=682. Acesso em: 25 dez. 2012.

CALDERONI, S. Os bilhões perdidos no lixo. São Paulo: Ed. Humanitas, 1997.

CELLARD, A. A análise documental. In: POUPART, J. et al. A pesquisa qualitativa: enfoques epistemológicos e metodológicos. Petrópolis, Vozes, 2008.

CHIZZOTTI, A. Pesquisa qualitativa em ciências humanas e sociais. Petrópolis, Vozes, 2006.

DIAS, G.F. Educação Ambiental: Princípios e Práticas, São Paulo. Global, 1998.

GRUN, M. Ética e Educação Ambiental: a conexão necessária. Campinas, SP:Papirus, 1996.

GOMES, D.V. Educação para o consumo ético e sustentável. Revista Eletrônica do Mestrado em Educação Ambiental. V. 16, jan. a jun., 2006.

GOMES, D.V. A importância do estudo da cidadania na efetivação do direito fundamental ao meio ambiente ecologicamente equilibrado. Dissertação de Mestrado: Caxias do Sul: 2007.

GUIMARÃES R. Modernidad, medio ambiente y etica. Ambient soc. 1998; $1(2): 5-24$.

JACOBI P. Meio ambiente urbano e sustentabilidade: alguns elementos para a reflexão. In: CAVALCANTI C. (org.). Meio ambiente, desenvolvimento sustentável e políticas públicas. São Paulo: Cortez; 1997.

GUIMARÃES, M. A Dimensão Ambiental na Educação. Campinas: Papirus, 1995.

HAGUETTE, T.M.F. Metodologias qualitativas na Sociologia. $5^{\circ}$ edição. Petrópolis: Vozes, 1997.

LAKATOS, E.M.; MARCONI, M.A. Técnicas de pesquisa. $3^{\circ}$ edição. São Paulo: Editora Atlas, 1996. 
LAYRARGUES, P.P. Educação no processo de gestão ambiental. Anais do SIMPÓSIO SUL BRASILEIRO DE EDUCAÇÃO AMBIENTAL, 1. Simpósio Gaúcho de Educação STONER, J. A. F; FREEMAN, R. E. Administração. Rio de Janeiro: Prentice-Hall do Brasil, 1999

LEFF, E. Saber Ambiental: Sustentabilidade, racionalidade, complexidade, poder. Petrópolis: Vozes, 2001.

LEFF, E. Educação Ambiental e desenvolvimento sustentável. In: REIGOTA, M. (org.). Verde cotidiano: o meio ambiente em discussão. Rio de Janeiro: DP\&A, 1999.

PEREIRA NETO, J.T. Conceitos modernos de compostagem. Engenharia Sanitária, v.28, n.2, p.104-109, 1989.

PEREIRA, S.R. Subcentro se Condições de vida no Jardim Bongiovani e Conjunto Habitacional Ana Jacinta - Presidente Prudente (SP). Presidente Prudente, Dissertação de Mestrado em Geografia: UNESP, 2001. 